\title{
Willingness to perform induced abortion and associated factors among graduating midwifery, medical, nursing, and public health officer students of University of Gondar, Northwest Ethiopia: institution based cross sectional study
}

Mihretu Molla Enyew(o)

\begin{abstract}
Background: In developing countries, abortion is often unsafe and a significant cause of maternal morbidity and mortality accounting for about $8 \%(4.7-13.2 \%)$ of maternal mortality worldwide. Internationally, safe abortion services are recognized as reducing maternal mortality, and liberalized abortion laws are associated with reduced mortality resulting from unsafe abortion procedures. However, health care providers have moral, social and genderbased reservations that affects their willingness towards providing induced abortion services. The purpose of this study was to assess willingness to perform induced abortion and associated factors among graduating Midwifery, Medical, Nursing, and Public health officer students of University of Gondar.

Methods: Institution based cross sectional study was conducted from March 29 to May 30, 2019. All graduating students available during data collection period were considered as study population. Stratified simple random sampling technique was used to select 424 study participants. Pre tested, semi- structured, self-administered questionnaire was used to collect data. Data analysis was done using SPSS version 20. Ethical clearance was obtained from School of midwifery under the delegation of institutional review board of university of Gondar.

Results: Two hundred ninety students out of 424 students were willing to perform induced abortion for indications supported by Ethiopian abortion law, making a proportion of $68.4 \%(95 \% \mathrm{Cl}: 64.2,72.9)$. Sex (Being male ( $\mathrm{AOR}=4.89$, $95 \% \mathrm{Cl}: 3.02,7.89)$ ), religion (being orthodox than protestant $(\mathrm{AOR}=10.41,95 \% \mathrm{Cl}: 3.02,21.57)$ ), being Muslim than protestant $(A O R=5.73,95 \% \mathrm{Cl}: 1.37,15.92))$ and having once or less a week religious attendance $(A O R=2.00,95 \%$ $\mathrm{Cl}: 1.20,3.34)$ were factors associated with willingness towards performing induced abortion.

Correspondence: mihretumolla143@gmail.com

Department of Clinical Midwifery, School of Midwifery, College of Medicine

and Health Sciences, University of Gondar, PO box 196, Gondar, Ethiopia

C C The Author(s). 2020 Open Access This article is licensed under a Creative Commons Attribution 4.0 International License, which permits use, sharing, adaptation, distribution and reproduction in any medium or format, as long as you give appropriate credit to the original author(s) and the source, provide a link to the Creative Commons licence, and indicate if changes were made. The images or other third party material in this article are included in the article's Creative Commons licence, unless indicated otherwise in a credit line to the material. If material is not included in the article's Creative Commons licence and your intended use is not permitted by statutory regulation or exceeds the permitted use, you will need to obtain permission directly from the copyright holder. To view a copy of this licence, visit http://creativecommons.org/licenses/by/4.0/ The Creative Commons Public Domain Dedication waiver (http://creativecommons.org/publicdomain/zero/1.0/) applies to the data made available in this article, unless otherwise stated in a credit line to the data. 
(Continued from previous page)

Conclusions: According to this study willingness of students towards providing induced abortion services was good. However female students, protestant followers and those students with more than once a week religious attendance should be encouraged to support women's access to induced abortion services by referring them to other health care professionals willing to provide induced abortion services.

Keywords: Willingness, Induced abortion, Graduating students, Ethiopian abortion law

\section{Background}

Over 25 million unsafe abortions occurred every year worldwide, the majority (97\%), occurred in developing countries, attributing $4.7-13.2 \%$ of maternal deaths annually $[1,2]$. In Ethiopia about $36 \%$ of adolescents, $39 \%$ of women within $20-24$ years of age, $54 \%$ of women within 25-29 years of age and $78 \%$ of women who are 35 and older years of age commit clandestine abortion which is potentially unsafe [3]. Induced abortion (safe termination) services are recognized as key interventions in reducing maternal mortality and morbidity associated with unsafe abortion procedures $[4,5]$. However, health care providers in Sub-Saharan Africa (SSA) have moral, social and gender based reservations that affect their willingness towards performing induced abortion [6]. As a result, complication of unsafe abortion is among the leading cause of maternal morbidities and mortalities in the region [7].

The government of Ethiopia revised and liberalized the abortion law in 2005 to increase the accessibility of safe termination services by taking the amount of unsafe abortion and its health detrimental consequences on maternal health [8]. However, a major reduction of morbidity and mortality from the complication of unsafe abortion has not yet been achieved [9]. The shortage of health care providers who can provide comprehensive abortion care (CAC) is still critical and this is again exacerbated by the unwillingness of some health care providers to provide induced abortion services due to various religious, cultural and biological factors $[10,11]$.

Graduating students' willingness towards induced abortion provision is an important influence on their intention and capacity to provide induced abortion services during their future careers [12]. Even though there is no concrete evidence in Ethiopia, studies done in Asia and Africa revealed a significant level of unwillingness towards performing induced abortion by graduating students in their future careers. For instance, medical students involved in a study done in Maharastra (India) described fear due to social norms and illegality of the procedure to provide abortion in their future practice [13]. Another study done in South Africa (SA) revealed only $23 \%$ of students were willing to perform induced abortions once they are qualified [14]. Thus, this study will have a fundamental role in pinpointing recommendations to develop positive attitude among graduating students towards providing safe abortion care services thereby reducing maternal morbidity and mortality.

\section{Methods}

\section{Study design and period}

Institution-based cross-sectional study was conducted from March 29 to May 30, 2019.

\section{Study setting}

University of Gondar, College of medicine and health sciences located in Gondar city, Northwest Ethiopia. The University of Gondar is one of the oldest and most well-established higher education institutions in the country. There were a total of 805 graduating Midwifery, Medicine, Nursing and public health officer (PHO) students in the College of Medicine and Health Sciences for 2018/19 academic year.

\section{Characteristics of participants}

Proportionally selected graduating midwifery, medical, nursing, and PHO of 2018/19 academic year were included in the study. Students who were not available due to social or medical reasons during the data collection period were excluded.

\section{Sampling}

Sample size was calculated using single population proportion sample size calculation formula. Assuming willingness of students to be $50 \%, Z \alpha / 2$ value of 1.96 and marginal error of $5 \%$, Sample size was calculated as follows:

$$
\begin{aligned}
& \mathrm{n}=(\mathrm{Z} \alpha / 2)^{2} \mathrm{pq} / \mathrm{w}^{2} \\
& \mathrm{n}=(1.96)^{2}(.5)(.5) /(0.05)^{2} \\
& n=385 \\
& \text { Adding } 10 \% \text { non-response rate } \\
& \mathbf{N}_{\mathbf{f}}=\mathbf{4 2 4}
\end{aligned}
$$

Stratified random sampling technique was used to select study participants (Fig. 1).

\section{Variables of the study}

Dependent variable

- willingness of graduating students (willing, not willing) 


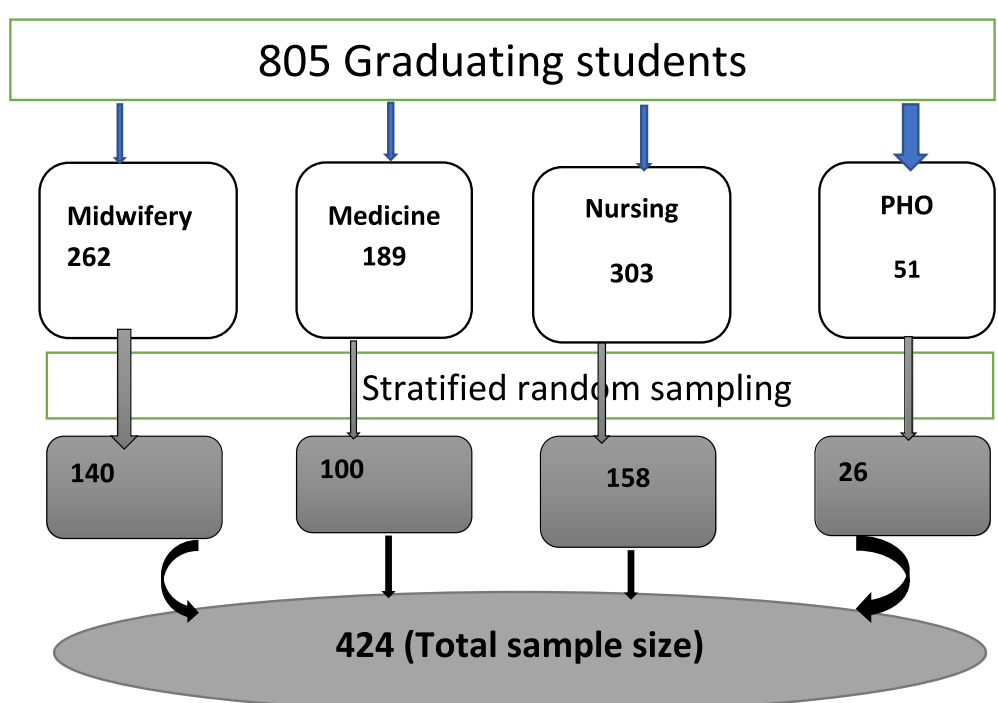

Fig. 1 Schematic presentation of enrolment of study participants of willingness to perform induced abortion and associated factors among graduating midwifery, medical, nursing and PHO students of university of Gondar, 2019. N=424

Independent variables

- Age, field of study, marital status, religion, ethnicity, sex, family place of residence, frequency of religious attendance, exposure to sexual practice, exposure to abortion care services

\section{Operational definitions Willingness of graduating students}

Status and level of willingness of students in performing induced abortion following graduation for indications supported by Ethiopian abortion law.

\section{Induced abortion}

Deliberate termination of pregnancy before viability for reasons of nationally liberalized indications.

\section{Liberalized components of induced/safe abortion services}

Nationally supported indications to terminate pregnancy such as pregnancy following rape, pregnancy following incest, minority pregnancy, pregnancy endangering the woman's life and pregnancy complicated by gross fetal defects [15].

\section{Data collection tools and procedures}

Data were collected by self-administered interviews using a semi-structured and pre-tested questionnaire. Six Bsc midwives and two Msc midwives were assigned to collect data and to supervise the data collection process respectively. The questionnaire used to collect data was developed for this study (Additional file 1: Annex).

\section{Data quality control}

The quality of data was assured by proper designing and pre-testing of the questionnaires on $5 \%$ of study participants at Debretabor University and by giving training for the data collectors and supervisors before the actual data collection. Every day after data collection, questionnaires were reviewed and checked for consistency and completeness by the supervisors. Data clean up and crosschecking was done before analysis.

\section{Data processing and analysis}

All the questionnaires were checked for completeness, manually and coded, then entered into Epi info 7 and exported to SPSS version 20 software package for further analysis. Descriptive analysis results were presented in the form of table, figure, and text using frequencies and summary statistics such as mean, standard deviation and percentage. Bivariate logistic regression analysis was used to determine the association of each independent variable with the outcome variable and multivariable logistic regression analysis was employed to adjust the influence of various independent variables (confounding effects) on the outcome variable. Odds ratio (OR) with 95\% confidence interval (CI) was used to see the association between independent variables and the dependent variable.

\section{Results}

\section{Socio-demographic characteristics}

A total of 424 graduating students were included in the study, making a $100 \%$ response rate. The age of the study participants was between 20 and 30 years with mean $( \pm$ SD) age $23.15 \pm 1.77$ years (Table 1$)$. 
Table 1 Socio demographic characteristics of study participants of attitudes and associated factors on induced abortion among graduating midwifery, medical, nursing and health officer students of university of Gondar, northwest Ethiopia, 2018. $n=424$

\begin{tabular}{|c|c|c|}
\hline Variable & Frequency & Percent (\%) \\
\hline \multicolumn{3}{|l|}{ Age } \\
\hline $20-24$ & 372 & 87.7 \\
\hline $25-29$ & 42 & 9.9 \\
\hline $30-35$ & 10 & 2.4 \\
\hline \multicolumn{3}{|l|}{ Sex } \\
\hline Male & 225 & 53.1 \\
\hline Female & 199 & 46.9 \\
\hline \multicolumn{3}{|l|}{ Field of study } \\
\hline Midwifery & 140 & 33 \\
\hline Medicine & 100 & 23.6 \\
\hline Nursing & 158 & 37.3 \\
\hline Public health officer & 26 & 6.1 \\
\hline \multicolumn{3}{|l|}{ Family place of residence } \\
\hline Urban & 149 & 35.1 \\
\hline Rural & 275 & 64.9 \\
\hline \multicolumn{3}{|l|}{ Marital status } \\
\hline Single & 392 & 92.5 \\
\hline Married & 32 & 7.5 \\
\hline \multicolumn{3}{|l|}{ Religion } \\
\hline Orthodox & 339 & 80 \\
\hline Muslim & 64 & 15 \\
\hline Protestant & 21 & 5 \\
\hline \multicolumn{3}{|l|}{ Ethnicity } \\
\hline Amhara & 245 & 57.8 \\
\hline Kemant & 47 & 11.1 \\
\hline Oromo & 56 & 13.2 \\
\hline Tigray & 23 & 5.4 \\
\hline Sidama & 47 & 11.1 \\
\hline Others $^{\mathrm{a}}$ & 6 & 1.4 \\
\hline \multicolumn{3}{|c|}{ Religious service attendance } \\
\hline More than once a week & 279 & 65.8 \\
\hline Once a week or less & 145 & 34.2 \\
\hline \multicolumn{3}{|c|}{ Exposure to sexual practice } \\
\hline Yes & 124 & 29.4 \\
\hline No & 300 & 70.6 \\
\hline \multicolumn{3}{|c|}{ Exposure to abortion care services } \\
\hline Yes & 377 & 88.9 \\
\hline No & 47 & 11.1 \\
\hline
\end{tabular}

Others $^{\mathrm{a}}$ : Gurage, Somali, Hadiya, Wolayta, Kembata

\section{Willingness of students towards performing induced} abortion

Of the total 424 study participants, 290 of them were willing to perform induced abortion for indications supported by law, making a proportion of $68.4 \%(95 \% \mathrm{Cl}$ : $64.2,72.9$ ). About $70.7 \%$ of midwifery students, $61 \%$ of medical students, $72.8 \%$ of nursing students and $57.7 \%$ of $\mathrm{PHO}$ were willing to provide induced abortion services (Fig. 2).

\section{Factors associated with willingness of graduating students towards performing induced abortion}

In bivariate logistic regression analysis, willingness towards performing induced abortion was associated with male sex, single marital status, urban family place of residence, orthodox and Muslim religions and frequent religious attendance.

Among variables found to be significantly associated with willingness towards doing induced abortion using bivariate logistic regression analysis, male sex (AOR = 4.89, 95\%CI: 3.02, 7.89), being orthodox than protestant $(\mathrm{AOR}=10.41,95 \% \mathrm{CI}: 3.02,21.57)$ being Muslim than protestant $(\mathrm{AOR}=5.73,95 \% \mathrm{CI}: 1.37,15.92)$ and less than once a week religious attendance $(\mathrm{AOR}=2.00,95 \%$ CI: $1.20,3.34)$ were also found to be significantly associated in multivariate logistic regression analysis (Table 2).

\section{Discussion}

This study assessed willingness of graduating midwifery, medical, nursing and PHO students towards providing induced abortion services and found 290 students out of 424 students willing to perform induced abortion for indications supported by law, making a proportion of $68.4 \%$ (95\% Cl: 64.2, 72.9). This finding was in line with findings in California-66.21\% [16] and Poland-70\% [17].

The result was high when compared with a study done in Argentina-3.34\% [18]. This was mainly due to lack of accurate information about legal frameworks of abortion care provision by the Argentinian side. The finding was also high when compared with another study done in Canada [19] where fewer than $30 \%$ of students planned to provide any type of abortion. The possible explanation might be Lack of perceived social support for providing $C A C$ and lack of interest to specialize in health care fields containing abortion by Canadian students. The result was also high when compared with a study done Turkey-50.1\% [20] and Iran-43.7\% [21] respectively. This difference might be due to religious preferences as these two countries are being governed by strict Islamic doctrines. The magnitude was again high when compared with the finding Ireland-58.8\% [22]. This might be due to the difference in the year of study of students as the later were not graduating students. 


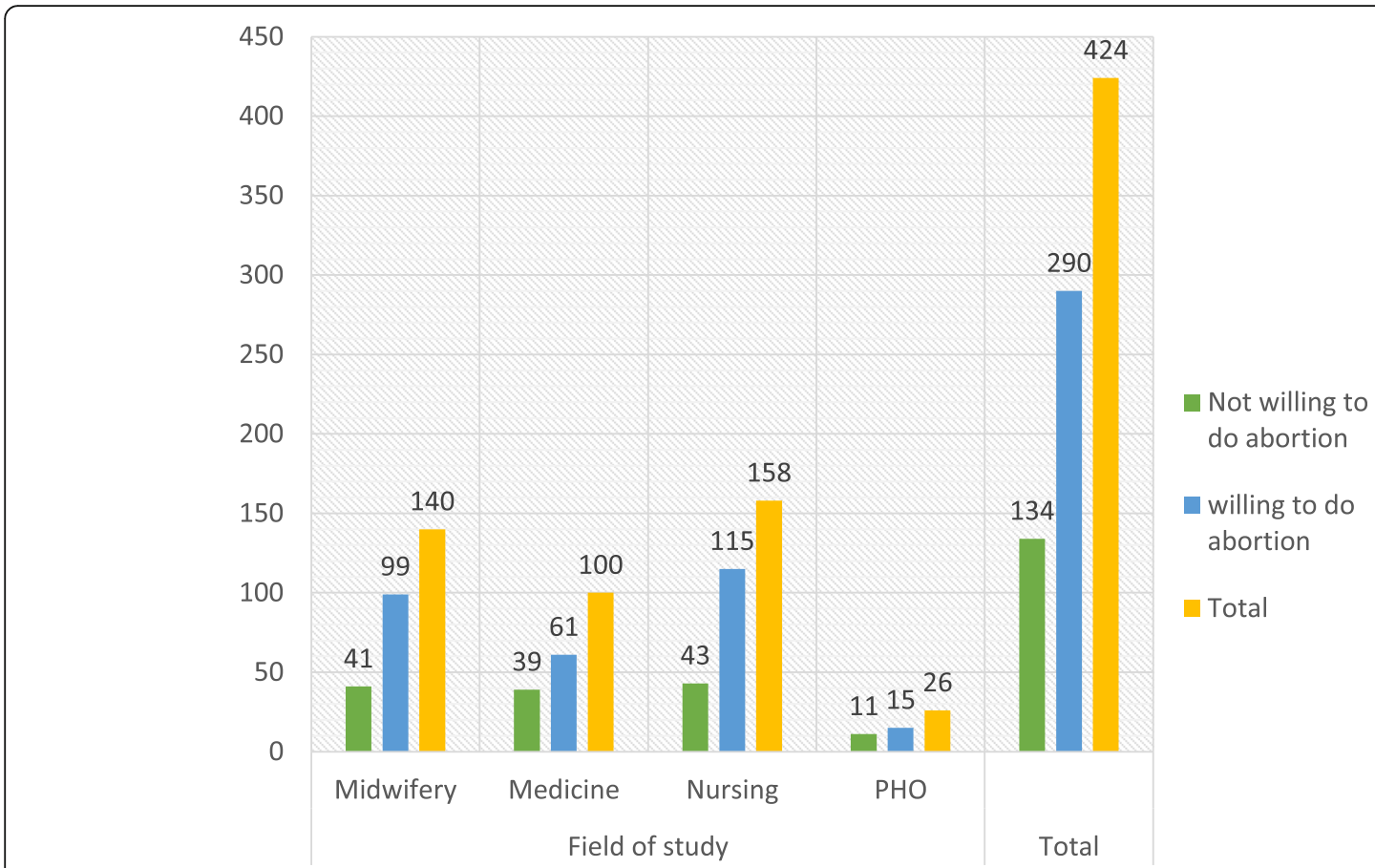

Fig. 2 Proportion of willing students to perform induced abortion among graduating midwifery, medical, nursing and PHO students of university of Gondar, 2019. N=4

Table 2 Bivariate and multivariate logistic regression analysis of Factors Associated with willingness towards performing induced abortion among graduating midwifery, medical, nursing and health officer students of university of Gondar, northwest Ethiopia, 2018. $n=424$

\begin{tabular}{|c|c|c|c|c|c|}
\hline \multirow[t]{2}{*}{ Variable } & \multicolumn{2}{|c|}{ Willing to do abortion } & \multirow[t]{2}{*}{ COR $(95 \% \mathrm{Cl})$} & \multirow[t]{2}{*}{ AOR $(95 \% \mathrm{Cl})$} & \multirow{2}{*}{$\begin{array}{l}P \\
\text { value }\end{array}$} \\
\hline & Yes & No & & & \\
\hline Sex & Frq & Frq & & & \\
\hline Male & 189 & 36 & $5.09(3.24,8.01)$ & $4.89(3.02,7.89)$ & .000 \\
\hline Female & 101 & 98 & Reference & & \\
\hline \multicolumn{6}{|l|}{ Family residence } \\
\hline Urban & 116 & 33 & $2.04(1.29,3.23)$ & $1.52(0.91,2.54)$ & .108 \\
\hline Rural & 174 & 101 & Reference & & \\
\hline \multicolumn{6}{|l|}{ Marital status } \\
\hline Single & 281 & 111 & $6.47(2.90,14.42)$ & $1.59(0.58,4.32)$ & .369 \\
\hline Married & 9 & 23 & Reference & & \\
\hline \multicolumn{6}{|l|}{ Religion } \\
\hline Orthodox & 249 & 90 & $16.60(4.78,57.69)$ & $10.41(3.02,21.57)$ & .000 \\
\hline Muslim & 38 & 26 & $8.77(2.34,32.83)$ & $5.73(1.37,15.92)$ & .017 \\
\hline Protestant & 3 & 18 & Reference & & \\
\hline \multicolumn{6}{|c|}{ Religious attendance } \\
\hline$\leq$ once a week & 116 & 29 & $2.41(1.50,3.88)$ & $2.00(1.20,3.34)$ & .008 \\
\hline > once a week & 174 & 105 & Reference & & \\
\hline
\end{tabular}


Male students were about five times $(\mathrm{AOR}=4.89$, $95 \%$ CI: $3.02,7.89)$ more likely to provide induced abortion services than their female counterparts. This finding is contrary to the findings of previous studies done in Iran [23]. The possible explanation might be long-lasting male dominance in every aspects of participation in our country when compared with Iran.

Concerning students' religion, being orthodox were about ten times (AOR $=10.41,95 \% \mathrm{CI}$ : 3.02, 21.57) more likely to show willingness to induced abortion services than being protestant. Being Muslim was also about six times $(\mathrm{AOR}=5.73,95 \% \mathrm{CI}: 1.37,15.92)$ more likely to show willingness to induced abortion services than being protestant. This finding is in line with the findings of the studies done SSA [6], SA [14], Iran [21] and Ethiopia [10]. This might be tailored to the fact that religious restrictions of newly introduced Protestantism might have been practiced better than those of relatively older doctrines.

Those students who had religious attendance less than once a week irrespective of the type of religion were two times $(\mathrm{AOR}=2.00,95 \% \mathrm{CI}: 1.20,3.34)$ more likely to show willingness to induced abortion services than those who had more than once a week religious attendance. This finding was consistent with the finding of the study done in Iran and Chile (20, [15]). The possible explanation might be the more students attend religious activities the more they become conservative in providing induced abortion services as they might directly link it with doing sin and vice versa.

\section{Conclusions}

According to this study willingness of graduating students towards performing induced abortion was good when compared with other findings. However female students, protestant followers and those students with more than once a week religious attendance should be encouraged to support women's access to induced abortion services by referring them to other health care professionals willing to provide induced abortion services.

\section{Supplementary Information}

The online version contains supplementary material available at https://doi. org/10.1186/s12884-020-03382-0.

Additional file 1. Annex Questionnaire to assess Willingness to perform induced abortion and associated factors among graduating Midwifery, Medical, Nursing, and Public health officer students of University of Gondar, Northwest Ethiopia.

\section{Abbreviations}

AOR: Adjusted Odds Ratio; CAC: Comprehensive Abortion Care; Cl: Confidence Interval; COR: Crude Odds Ratio; EMwA: Ethiopian Midwives Association; Frq: Frequency; IRB: Institutional Review Board; Km: Kilo Meters; $\mathrm{N}_{\mathrm{f}}$ : Final Sample size; PHO: Public Health Officer; SA: South Africa; SPSS: Statistical Package for Social Sciences; SSA: Sub- Saharan Africa; ST: Safe
Termination; UNICEF: United Nations International Children's Emergency Fund; WHO: World Health Organization

\section{Acknowledgments}

I would like to thank the Ethiopian midwives Association for providing such a chance and Amplify change for its genuine financial support.

I would also like to thank college of medicine and health science register workers who provide me all the necessary information concerning my study area.

I would also very delighted to thank study participants, data collectors, and supervisors.

Finally, I would also like to thank Mr. Addisu Fekadu for his smart communication skills and genuine coordination of this research project from the inception to the end.

\section{Author's contributions}

ME: wrote the proposal, supported and supervised data collection, analyzed the data, drafted the paper and prepare the final manuscript. The author read and approved the final manuscript.

\section{Funding}

The funding body (Ethiopian Midwives association in collaboration with Amplify change) had a role in the coverage of the financial costs related to the design and data collection of this study. However, the funding body had no role in the analysis, interpretation of data and in writing of the manuscript.

\section{Availability of data and materials}

All data generated or analysed during this study are included in this published article and in its supplementary information files.

\section{Ethics approval and consent to participate}

Ethical approval was obtained from department of midwifery under the delegation of Institutional Review Board (IRB) of University of Gondar. Written informed consent was obtained from each study subject before data collection process. During data collection process the data collectors informed each study participant about the purpose and anticipated benefits of the research project and the study participants were also informed on their full right to refuse, withdraw or completely reject part or all of their part in the study. They were also informed that all data obtained from them would be kept confidential by using codes instead of any personal identifiers.

\section{Consent for publication}

Not applicable.

\section{Competing interests}

The author declare that he has no competing interests.

Received: 15 June 2020 Accepted: 29 October 2020

Published online: 10 November 2020

\section{References}

1. Ganatra B, Gerdts C, Rossier C, Johnson BR Jr, Tunçalp Ö, Assifi A, et al. Global, regional, and subregional classification of abortions by safety, 201014: estimates from a Bayesian hierarchical model. Lancet. 2017;390(10110): 2372-81.

2. Say L, Chou D, Gemmill A, Tuncalp O, Moller AB, Daniels J, et al. Global causes of maternal death: a WHO systematic analysis. Lancet Glob Health. 2014;2(6):e323-33.

3. Sully E, Dibaba Y, Fetters T, Blades N, Bankole A. Playing it safe: legal and clandestine abortions among adolescents in Ethiopia. J Adolesc Health. 2018;62(6):729-36

4. Ganatra B, Faundes AJBP, Obstetrics RC. Role of birth spacing, family planning services, safe abortion services and post-abortion care in reducing maternal mortality. Best Pract Res Clin Obstet Gynaecol. 2016;36:145-55.

5. Lim LM, Singh KJBP, Obstetrics RC. Termination of pregnancy and unsafe abortion. Best Pract Res Clin Obstet Gynaecol. 2014;28(6):859-69.

6. Loi UR, Gemzell-Danielsson K, Faxelid E, Klingberg-Allvin M. Health care providers' perceptions of and attitudes towards induced abortions in sub- 
Saharan Africa and Southeast Asia: a systematic literature review of qualitative and quantitative data. BMC Public Health. 2015;15(1):139.

7. Gebremedhin M, Semahegn A, Usmael T, Tesfaye GJ Sr. Unsafe abortion and associated factors among reproductive aged women in Sub-Saharan Africa: a protocol for a systematic review and meta-analysis. Syst Rev. 2018; 7(1):130.

8. Wada TJ. Abortion law in Ethiopia: a comparative perspective. Mizan Law Review. 2008;2(1):1-32.

9. Gebrehiwot Y, Fetters T, Gebreselassie H, Moore A, Hailemariam M, Dibaba $Y$, et al. Changes in morbidity and abortion care in Ethiopia after legal reform: National results from 2008 and 2014. Int Perspect Sex Reprod Health. 2016;42(3):121.

10. Holcombe SJ, Berhe A, Cherie A. Personal beliefs and professional responsibilities: Ethiopian midwives' attitudes toward providing abortion services after legal reform. Stud Fam Plann. 2015:46(1):73-95.

11. Sintayehu Y, Hordofa B, Shiferaw K. Health Care Providers' Perception and Associated Factors towards Safe Abortion in Selected Health Facilities in Adama, Ethiopia. J Women's Health Care. 2018;7(428):2167-0420.1000428.

12. Teffo ME, Rispel LC. 'I am all alone': factors influencing the provision of termination of pregnancy services in two South African provinces. Glob Health Action. 2017;10(1):1347369.

13. Sjöström S, Essén B, Gemzell-Danielsson K, Klingberg-Allvin M. Medical students are afraid to include abortion in their future practices: in-depth interviews in Maharastra, India. BMC Med Educ. 2016;16(1):8.

14. Wheeler SB, Zullig LL, Reeve BB, Buga GA, Morroni C. Attitudes and intentions regarding abortion provision among medical school students in South Africa. Int Perspect Sex Reprod Health. 2012;38(3):154-63.

15. Biggs MA, Casas L, Ramm A, Baba CF, Correa SV, Grossman D. Future health providers' willingness to provide abortion services following decriminalisation of abortion in Chile: a cross-sectional survey. BMJ Open. 2019;9(10):e030797.

16. Rosenheck RE, Feigal C, Brown N, Barcellos T, Bender N. Attitudes on abortion: a cross-sectional analysis of medical students in their preclinical years [3F]. Obstet Gynecol. 2016;127:51S

17. Michalik A, Zdun-Ryżewska A, Pięta B, Basiński K, Kiełbasińska J, Mazurkiewicz $B$, et al. Multicenter study on midwifery students' attitudes towards abortion and it's place in their future practice-comparison of respondents at early and late stages of the university education. Nurse Educ Pract. 2019;35:42-7.

18. Ramos S, Romero M, Michel AR. Health care providers' opinions on abortion: a study for the implementation of the legal abortion public policy in the province of Santa Fe, Argentina. Reprod Health. 2014;11(1):72.

19. Myran DT, Carew CL, Tang J, Whyte H, Fisher WA. Medical students' intentions to seek abortion training and to provide abortion services in future practice. J Obstet Gynaecol Can. 2015:37(3):236-44.

20. Kesen NF, Polat G, Daşbaş S. Opinions on abortion among a group of university students in Turkey. Int J Humanit Soc Sci. 2015;7(1):89-95.

21. Inaloo R, Tghipour N, Razeghi A, Rahmanian E. Attitudes of students of Jahrom University of medical sciences towards abortion: a descriptive, cross-sectional study. J Fundamental Appl Sci. 2018;10(6S):80-91.

22. Fitzgerald JM, Krause KE, Yermak D, Dunne S, Hannigan A, Cullen W, et al. The first survey of attitudes of medical students in Ireland towards termination of pregnancy. J Med. 2014;40(10):710-3.

23. Yanikkerem E, Üstgörül S, Karakus A, Baydar O, Esmeray N, Ertem G. Turkish nursing students' attitudes towards voluntary induced abortion. J Pakistan Med Assoc. 2018:68(3):410-6.

\section{Publisher's Note}

Springer Nature remains neutral with regard to jurisdictional claims in published maps and institutional affiliations.

Ready to submit your research? Choose BMC and benefit from:

- fast, convenient online submission

- thorough peer review by experienced researchers in your field

- rapid publication on acceptance

- support for research data, including large and complex data types

- gold Open Access which fosters wider collaboration and increased citations

- maximum visibility for your research: over $100 \mathrm{M}$ website views per year

At BMC, research is always in progress.

Learn more biomedcentral.com/submissions 